\title{
Investigation of bar parameters occurred by cross-shore sediment transport
}

\author{
Mustafa Demirci ${ }^{1}$ and M. Sami Aköz ${ }^{2}$ \\ ${ }^{1}$ Mustafa Kemal University, Engineering Faculty, Civil Engineering Department, İskenderun, Hatay-Turkey \\ ${ }^{2}$ Çukurova University, Engineering and Architecture Faculty, Civil Engineering Department, Adana-Turkey
}

\begin{abstract}
Cross-shore sediment transport is very important factor in the design of coastal structures, and the beach profile is mainly affected by a number of parameters, such as wave height and period, beach slope, and the material properties of the bed. In this study cross-shore sediment movement was investigated using a physical model and various offshore bar geometric parameters were determined by the resultant erosion profile. The experiments on cross- shore sediment transport carried out in a laboratory wave channel for initial base slopes of 1/8, 1/10 and 1/15. Using the regular waves with different deep-water wave steepness generated by a pedal-type wave generator, the geometrical of sediment transport rate and considerable characteristics of beach profiles under storm conditions and bar parameters affecting on-off shore sediment transport are investigated for the beach materials with the medium diameter of $d_{50}=0.25$, $0.32,0.45,0.62$ and $0.80 \mathrm{~mm}$. Non-dimensional equations were obtained by using linear and non-linear regression methods through the experimental data and were compared with previously developed equations in the literature. The results have shown that the experimental data fitted well to the proposed equations with respect to the previously developed equations.
\end{abstract}

KEY WORDS: Cross-shore sediment transport; Bar parameters; Regression analysis; Experimental study.

\section{INTRODUCTION}

Most problems of coastal engineering are dependent on a number of parameters. There are lots of parameters affect design of coastal structures such as the wave height and period, the beach slope and the properties of the bed. Bar parameters caused by cross-shore sediment transport are very important for design of coastal structures. Various parameters such as wave conditions, bed slope, and characteristics of sediment particles affect the cross-shore sediment transport discharge and consequently the coastal profiles. There are many theoretical and experimental studies which carried out by researchers. Previously studies in this subject are summarized as follows. Cross-shore sediment transport and on coastal features consequential of diverse factors were studied by (Saville, 1957; Dean, 1973; Noda, 1972; Gourlay, 1980; Sawaragi and Deguchi, 1980). Beach profiles were classified such as by Johnson (1949), Iwagaki and Noda (1962), Nayak (1970) and Hattori and Kawamata (1980). A model was offered to describe onshore-offshore sand transport in the surf zone by Sunamura and Horikawa (1974). The model was based on the physical consideration that the net transport attains a state of equilibrium. They proposed beach classification based on displacement of topography from the initial beach slope. Using these parameters, the direction of onshore-offshore transport and the beach profile in the surf zone were expressed. Larson and Kraus (1989) studied erosion and deposition profiles and proposed a formula for bar parameters using experimental data as well as for erosion and deposition criteria. Silvester and Hsu

Corresponding author: Mustafa Demirci

e-mail:demircimustafa97@gmail.com 
(1997) determined beach profile parameters by non-linear regression techniques using various experimental data obtained from previous works. In this study, the proposed formula for bar parameters is given in Table 1. Watanabe et al. (1980) developed a three-dimensional numerical model to estimate cross-shore sediment transport. Larson (1996) produced a numerical model to compute cross-shore sediment transport and the beach profile under effects of regular waves and in this modeling, three cases of variation of profiles were studied. This model enables the investigation of bar-forming erosion in equilibrium, berm erosion and effects of broken waves on offshore bar; this model is well fitted for erosion conditions, but not for deposition conditions. Experimental and theoretical works carried out by Hsu (1998). He determined the geometry of offshore bar. He concluded that cross-shore waves traveling with variable angles make the beach profile be in equilibrium. Obtained equations for bar parameters are also given in Table 1. Ruessink et al. (2002) have made an attempt to determine long time variation of bar crest near beach profile using the remote sensing method. Günaydın and Kabdaşlı (2003) carried out experiments by studying the characteristics of coastal erosion using a model in which the mean diameter of particles and the beach slope are $0.35 \mathrm{~mm}$ and $1 / 5 \mathrm{under}$ regular and irregular wave conditions, respectively. Günaydın and Kabdaşlı (2005) also investigated the geometric characteristics of wave-induced offshore bars by using physical models. Both regular and irregular waves were used during the testing. The results of the experimental study were evaluated and some empirical expressions based upon the results are suggested to define those geometric parameters for pure regular waves, pure irregular waves and regular-irregular waves. Depend on surf similarity parameter $\left(\xi_{\theta}\right)$ produced equations for bar parameters are given Table 1. Kömürcü et al. (2007) carried out laboratory experiments to investigate cross-shore sediment transport. A regression analysis was made to establish the bar parameters which came out of the experiments and equations were constructed for the bar parameters. These bar parameters and corresponding equations (Eqs. (7)-(9)) are given in Table 1. Rozynski (2003) studied the association among the longtime observation values in cross shore sediment movement of the southwest Baltic coast made of material with a diameter of $0.22 \mathrm{~mm}$ by correlation analysis. An experimental investigation was carried out by Özölçer (2008) in a wave flume using regular waves, and geometric characteristics of erosion profile were determined by the resultant erosion profile. The results have shown that the experimental data fitted well to the proposed equations with respect to the previously developed equations. In Demirci and Aköz (2012), an experimental study was carried out to investigate the geometrical characteristics of beach profiles under storm conditions and the parameters affecting on-off shore sediment transport for the different beach materials. Experimenal results showed that the bar parameters were formed by the breaking waves and the bar parameters migrated with the increasing wave steepness.

In this study, experiments were carried out on cross-shore sediment transport in order to investigate the affecting bar parameters on-off shore sediment transport for five different beach materials of mean grain diameter $\mathrm{d}_{50}$ equal to $0.25,0.32,0.45$, 0.62 and $0.80 \mathrm{~mm}$. As result of this study, non dimensioanal equations for bar parameters were generated by using nonlinear regression methods.

Table 1 Currently used equations for determination of bar parameters.

\begin{tabular}{|c|c|c|}
\hline Authors & Bar parameters equations & Eq. no \\
\hline $\begin{array}{l}\text { Silvester and Hsu } \\
\text { (1997) }\end{array}$ & $\begin{array}{l}X_{b} / L_{0}=0.96\left(H_{0} / L_{0}\right) / \tan \beta \\
X_{t} / L_{0}=0.022+1.508\left(H_{0} / L_{0}\right) / \tan \beta+0.140\left[\left(H_{0} / L_{0}\right) / \tan \beta\right]^{2}\end{array}$ & $\begin{array}{l}(1) \\
(2)\end{array}$ \\
\hline $\begin{array}{l}\text { Hsu } \\
(1998)\end{array}$ & $\begin{array}{l}X_{b} / L_{0}=1.9 \xi_{\theta}^{-1.42} \\
X_{t} / L_{0}=0.40 \xi_{\theta}^{-1.12}\end{array}$ & $\begin{array}{l}\text { (3) } \\
\text { (4) }\end{array}$ \\
\hline $\begin{array}{l}\text { Günaydın and } \\
\text { Kapdaşlı (2005) }\end{array}$ & $\begin{array}{l}X_{b}=113.98\left(\tan \beta \sqrt{H_{0} / L_{o}}\right)^{1.9762} L_{0} \\
X_{t}=64.966\left(\tan \beta \sqrt{H_{0} / L_{o}}\right)^{1.6754} L_{0}\end{array}$ & $\begin{array}{l}\text { (5) } \\
\text { (6) }\end{array}$ \\
\hline $\begin{array}{c}\text { Kömürcü et al. } \\
\text { (2007) }\end{array}$ & $\begin{array}{l}X_{b} / L_{0}=0.5803+\exp \left(0.6508-11.471 m+9.0126\left(H_{o} / L_{o}\right)+0.0347\left(H_{o} / w T\right)\right. \\
X_{t} / L_{0}=-1.9728+\exp \left(1.9311-13.127 m+0.2706 T+34.662 H_{o}-1008.5 d_{50}\right) \\
X_{s}=0.7151 m^{-0.6804} T^{0.5947} H_{0}^{0.4864} d_{50}^{-0.1404}\end{array}$ & $\begin{array}{l}(7) \\
(8) \\
(9)\end{array}$ \\
\hline
\end{tabular}




\section{METHODS}

Under the storm conditions, experiments were carried out in a wave channel of $12 \mathrm{~m}$ in length, $0.40 \mathrm{~m}$ in width and $0.60 \mathrm{~m}$ in depth at Department of Civil Engineering, Cukurova University, Adana, Turkey. (Demirci, 2006). A series of laboratory experiments have been performed to investigate the variation of coastal profile under different scenarios (64 tests). The sloping beach and wave producer were located in the wave channel. Waves in the channel were produced by using the pedal type wave producer. Wave conditions chosen between maximum and minimum to originate erosion profile as would be in nature in order to examine considered parameters. In the tests, regular waves were between $7-14 \mathrm{~cm}$ high for period between 0.47 and $0.83 \mathrm{~s}$. In this work, three different beach slopes were used and values of these slopes both represent slopes in nature and make laboratory conditions easy. Bed slopes were $1 / 8,1 / 10$ and $1 / 15$, respectively. In this study, five different materials in which, mean diameters $\left(d_{50}\right)$ are $0.25,0.32,0.46,0.62$ and $0.80 \mathrm{~mm}$ were used. Experimental conditions and bar parameters are shown in Table 2 .

Table 2 Experimental conditions and bar parameters.

\begin{tabular}{|c|c|c|c|c|c|}
\hline $\begin{array}{l}\text { Total experiment } \\
\text { number }\end{array}$ & $\begin{array}{l}\text { Experiment } \\
\text { number }\end{array}$ & $\begin{array}{l}\text { Medium sediment } \\
\text { diameter } d_{50}(\mathrm{~mm})\end{array}$ & $\begin{array}{l}\text { Beach } \\
\text { slope }\end{array}$ & $\begin{array}{c}\text { Wave period } \\
T(\mathrm{~s})\end{array}$ & $\begin{array}{c}\text { Wave steepness } \\
\qquad\left(H_{0} / L_{0}\right)\end{array}$ \\
\hline 5 & NO.1 5 & \multirow{3}{*}{0.25} & $1 / 8$ & $0.60 \sim 0.83$ & $0.070 \sim 0.232$ \\
\hline 5 & NO.6 10 & & $1 / 10$ & $0.60 \sim 0.83$ & $0.070 \sim 0.232$ \\
\hline 5 & NO.11 15 & & $1 / 15$ & $0.60 \sim 0.83$ & $0.070 \sim 0.232$ \\
\hline 6 & NO.16 21 & \multirow{3}{*}{0.32} & $1 / 8$ & $0.52 \sim 0.83$ & $0.070 \sim 0.214$ \\
\hline 6 & NO.22 27 & & $1 / 10$ & $0.52 \sim 0.83$ & $0.070 \sim 0.214$ \\
\hline 4 & NO.28 31 & & $1 / 15$ & $0.60 \sim 0.76$ & $0.130 \sim 0.232$ \\
\hline 4 & NO.32 35 & \multirow{3}{*}{0.45} & $1 / 8$ & $0.60 \sim 0.76$ & $0.130 \sim 0.232$ \\
\hline 4 & NO.36 39 & & $1 / 10$ & $0.60 \sim 0.76$ & $0.130 \sim 0.232$ \\
\hline 4 & NO.40 43 & & $1 / 15$ & $0.60 \sim 0.76$ & $0.130 \sim 0.232$ \\
\hline 4 & NO.44 47 & \multirow{3}{*}{0.62} & $1 / 8$ & $0.60 \sim 0.76$ & $0.130 \sim 0.232$ \\
\hline 4 & NO.48 51 & & $1 / 10$ & $0.60 \sim 0.76$ & $0.130 \sim 0.232$ \\
\hline 3 & NO.52 54 & & $1 / 15$ & $0.60 \sim 0.76$ & $0.130 \sim 0.232$ \\
\hline 5 & NO.55 59 & \multirow{3}{*}{0.80} & $1 / 8$ & $0.47 \sim 0.76$ & $0.13 \sim 0.262$ \\
\hline 3 & NO.60 62 & & $1 / 10$ & $0.47 \sim 0.63$ & $0.257 \sim 0.263$ \\
\hline 2 & NO.63 64 & & $1 / 15$ & $0.52 \sim 0.63$ & $0.232 \sim 0.263$ \\
\hline
\end{tabular}

In order to investigate the sediment movement which occurs after the storm conditions and the resultant geometrical features of the beach profiles, the experimental conditions were arranged according to the parameter $\mathrm{C}$ (it would be greater than 8). $C$ parameter is in Eq. (4) given by Sunamura and Horikawa (1974).

$$
C=\frac{H_{0}}{L_{0}}(\tan \beta)^{0.27}\left(\frac{d_{50}}{L_{0}}\right)^{-0.67}
$$

where $\mathrm{C}$ is profile parameter, $\mathrm{H}_{0}$ is deep water wave height, $\mathrm{L}_{0}$ is deep water wave length, $\tan \beta$ is bottom slope, $\mathrm{d}_{50}$ is grain size. $\mathrm{C}$ is classified as follows.

$$
\begin{aligned}
& C<4 \quad \cdots \cdots \cdots \cdots \cdots \cdots \cdot \text { accretion-summer profile } \\
& 4<C<8 \quad \cdots \cdots \cdots . . . . \text { equilibrium profile } \\
& 8<\text { C ………..... erosion-winter profile }
\end{aligned}
$$


In the current study, cross-shore sediment transport and bar parameters under the storm conditions were investigated. The beach profiles which came out in different sediment diameters, coast slopes and bar parameters affecting the formation of profiles were investigated. Bar parameters which occurs as results of the beach erosion are investigated and given in Fig. 1. In the Fig. $1, \mathrm{X}_{\mathrm{b}}$ is horizontal distance between the initial bar point and original shoreline, $\mathrm{X}_{\mathrm{t}}$ is horizontal distance between the bar crest and original shoreline, $\mathrm{X}_{\mathrm{s}}$ is horizontal distance between the final bar point and the original shoreline, $\mathrm{H}$ is the wave height, $\mathrm{d}$ is the water depth, still-water level (SWL).

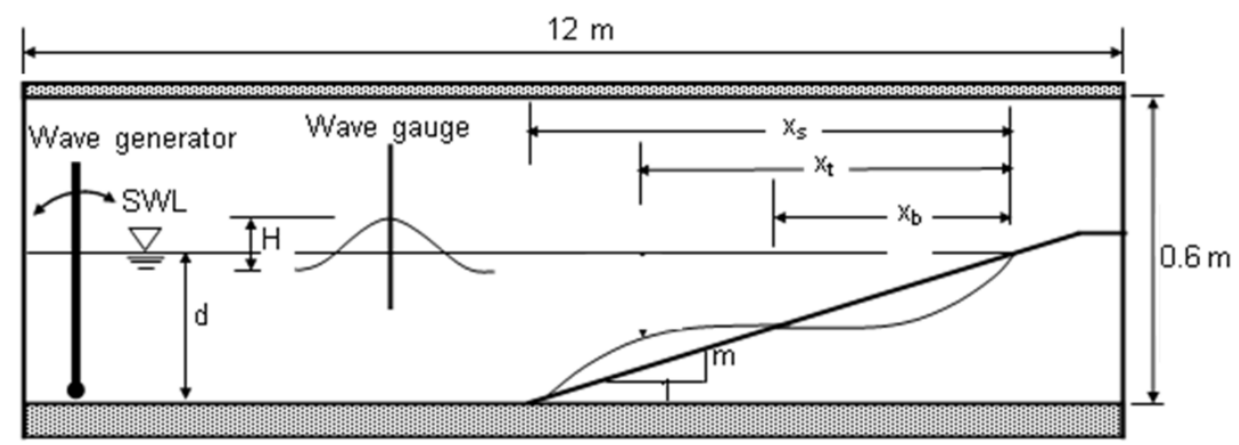

Fig. 1 Wave channel and experimental parameters.

\section{Analysis method of experimental results}

Experimental results were examined using linear and non-linear regression methods to obtain equations defining the bar parameters. Two equation types were determined in regression analyses, power (PF) and linear (LF). These functions are given respectively as follows:

$$
\begin{gathered}
y_{0}=b_{0} x_{1}^{b_{1}} x_{2}{ }^{b_{2}} x_{3}^{b_{3}} x_{4}{ }^{b_{4}} \ldots \ldots x_{n}{ }^{b n} \\
y_{o}=b_{0}+b_{1} x_{1}+b_{2} x_{2}+b_{3} x_{3}+\ldots \ldots . .+b_{n} x_{n}
\end{gathered}
$$

Experimental results were examined in detail and used to obtain the fittest equations containing bar parameters using nonlinear regression method. Different regression analyses were applied on bar parameters.

\section{Dimensional and non-dimensional variables}

Experimental results were made non-dimensional to minimize measurement errors due to laboratory conditions. In this study, non-dimensional bar parameters were used for estimation process. $\mathrm{X}_{\mathrm{b}}, \mathrm{X}_{\mathrm{t}}$ and $\mathrm{X}_{\mathrm{s}}$ considered as an independent variable and was obtained from dividing by $L_{0}, H_{0}$ and $d_{50}$. In constructing non-dimensional equations, independent variables, $\mathrm{m}, \mathrm{H}_{0} / \mathrm{L}_{0}$, $\mathrm{H}_{0} / \mathrm{d}_{50}$ and $\mathrm{H}_{0} / \mathrm{w}$ T were used in various combinations, in final expression $\mathrm{w}$ is the velocity of fall.

\section{RESULTS AND DISCUSSION}

In this study, bar parameters occurred by winter profiles under storm conditions were investigated. As a result of experimental study, bar parameters for each experiment were calculated. Regression analysis was implemented and non-dimensional equations were presented. Non-dimensional regression analysis was applied using results obtained from 64 experiments for $\mathrm{X}_{\mathrm{b}}$, $\mathrm{X}_{\mathrm{t}}$ and $\mathrm{X}_{\mathrm{s}}$. The determination coefficient for non-dimensional dependent and independent variable alternatives were computed by non-dimensional regression techniques using various function types.

The dimensionless dependent variables were used as $X_{b} / L_{0}, X_{b} / d_{50}, X_{b} / H_{0}$ for $\mathrm{X}_{\mathrm{b}}, X_{t} / L_{0}, X_{t} / d_{50}, X_{t} / H_{0}$ for $\mathrm{X}_{\mathrm{t}}, X_{s} / L_{0}, X_{s} / d_{50}$, $X_{s} / H_{0}$ for $\mathrm{X}_{\mathrm{s} .}$ The independent variables were used $\mathrm{m}, H_{0} / L_{0}$, and $H_{0} / d_{50}, H_{0} / w T$ for all parameters. Determination coefficients for alternatives of dimensionless dependent and independent variables were calculated and it is shown in Tables 3-5. 
Table 3 Determination coefficients for dimensionless alternatives variables for $\mathrm{X}_{\mathrm{b}}$.

\begin{tabular}{|c|c|c|c|}
\hline \multicolumn{2}{|c|}{ Status of the dimensionless variables } & \multirow{2}{*}{$\begin{array}{c}\text { For multi-linear } \\
\text { function } \mathrm{R}^{2}\end{array}$} & $\begin{array}{c}\text { For multi-hyperbolic } \\
\text { function } \mathrm{R}^{2}\end{array}$ \\
\hline \multirow{2}{*}{ Dependent variable } & Independent variable & 0.823 & 0.827 \\
\hline \multirow{2}{*}{$X_{b} / L_{0}$} & $m, H_{0} / L_{0}, H_{0} / w T, H_{0} / d_{50}$ & 0.775 & 0.782 \\
\cline { 2 - 4 } & $m, H_{0} / L_{0}, H_{0} / d_{50}$ & 0.717 & 0.688 \\
\cline { 2 - 4 } & $m, H_{0} / d_{50}, H_{0} / w T$ & 0.576 & 0.558 \\
\hline \multirow{3}{*}{$X_{b} / H_{0}$} & $m, H_{0} / L_{0}, H_{0} / w T, H_{0} / d_{50}$ & 0.507 & 0.462 \\
\cline { 2 - 4 } & $m, H_{0} / L_{0}, H_{0} / d_{50}$ & 0.513 & 0.466 \\
\cline { 2 - 4 } & $m, H_{0} / d_{50}, H_{0} / w T$ & 0.818 & 0.855 \\
\hline \multirow{2}{*}{$X_{b} / d_{50}$} & $m, H_{0} / L_{0}, H_{0} / w T, H_{0} / d_{50}$ & 0.797 & 0.823 \\
\cline { 2 - 4 } & $m, H_{0} / L_{0}, H_{0} / d_{50}$ & 0.798 & 0.825 \\
\hline
\end{tabular}

Table 4 Determination coefficients for dimensionless alternatives variables for $\mathrm{X}_{\mathrm{t}}$.

\begin{tabular}{|c|c|c|c|}
\hline \multicolumn{2}{|c|}{ Status of the dimensionless variables } & $\begin{array}{c}\text { For multi-linear } \\
\text { function } \mathrm{R}^{2}\end{array}$ & $\begin{array}{c}\text { For multi-hyperbolic } \\
\text { function } \mathrm{R}^{2}\end{array}$ \\
\hline \multirow{3}{*}{ Dependent variable } & Independent variable & 0.858 & 0.899 \\
\hline \multirow{3}{*}{$X_{t} / L_{0}$} & $m, H_{0} / L_{0}, H_{0} / w T, H_{0} / d_{50}$ & 0.734 & 0.785 \\
\cline { 2 - 4 } & $m, H_{0} / L_{0}, H_{0} / d_{50}$ & 0.577 & 0.660 \\
\cline { 2 - 4 } & $m, H_{0} / d_{50}, H_{0} / w T$ & 0.764 & 0.786 \\
\hline \multirow{3}{*}{$X_{t} / H_{0}$} & $m, H_{0} / L_{0}, H_{0} / w T, H_{0} / d_{50}$ & 0.594 & 0.569 \\
\cline { 2 - 4 } & $m, H_{0} / L_{0}, H_{0} / d_{50}$ & 0.665 & 0.632 \\
\cline { 2 - 4 } & $m, H_{0} / d_{50}, H_{0} / w T$ & 0.887 & 0.939 \\
\hline \multirow{2}{*}{$X_{t} / d_{50}$} & $m, H_{0} / L_{0}, H_{0} / w T, H_{0} / d_{50}$ & 0.866 & 0.877 \\
\cline { 2 - 4 } & $m, H_{0} / L_{0}, H_{0} / d_{50}$ & 0.855 & 0.895 \\
\cline { 2 - 4 } & $m, H_{0} / d_{50}, H_{0} / w T$ & & 0 \\
\hline
\end{tabular}

Table 5 Determination coefficients for dimensionless alternatives variables for $\mathrm{X}_{\mathrm{s}}$.

\begin{tabular}{|c|c|c|c|}
\hline \multicolumn{2}{|c|}{ Status of the dimensionless variables } & $\begin{array}{c}\text { For multi-linear } \\
\text { Function } \mathrm{R}^{2}\end{array}$ & $\begin{array}{c}\text { For multi-hyperbolic } \\
\text { Function } \mathrm{R}^{2}\end{array}$ \\
\hline \multirow{3}{*}{ Dependent variable } & Independent variable & 0.888 & 0.966 \\
\hline \multirow{3}{*}{$X_{s} / L_{0}$} & $m, H_{0} / L_{0}, H_{0} / w T, H_{0} / d_{50}$ & 0.786 & 0.831 \\
\cline { 2 - 4 } & $m, H_{0} / L_{0}, H_{0} / d_{50}$ & 0.645 & 0.701 \\
\cline { 2 - 4 } & $m, H_{0} / d_{50}, H_{0} / w T$ & 0.874 & 0.937 \\
\cline { 2 - 4 }$X_{S} / H_{0}$ & $m, H_{0} / L_{0}, H_{0} / w T, H_{0} / d_{50}$ & 0.700 & 0.698 \\
\cline { 2 - 4 } & $m, H_{0} / L_{0}, H_{0} / d_{50}$ & 0.769 & 0.764 \\
\hline \multirow{3}{*}{$X_{s} / d_{50}$} & $m, H_{0} / d_{50}, H_{0} / w T$ & 0.928 & 0.983 \\
\cline { 2 - 4 } & $m, H_{0} / L_{0}, H_{0} / w T, H_{0} / d_{50}$ & 0.875 & 0.919 \\
\cline { 2 - 4 } & $m, H_{0} / L_{0}, H_{0} / d_{50}$ & 0.896 & 0.937 \\
\hline
\end{tabular}


Table 6 Regression coefficients obtained from dimensionless regression analysis for $\mathrm{X}_{\mathrm{b}}$.

\begin{tabular}{|c|c|c|c|}
\hline \multicolumn{2}{|c|}{ Multi linear function } & Multi hyperbolic function \\
\hline $\begin{array}{c}\mathrm{X}_{\mathrm{b}} \\
\mathrm{L}_{0}\end{array} \mathrm{~b}_{0}+\mathrm{b}_{1} \mathrm{~m}+\mathrm{b}_{2} \frac{\mathrm{H}_{0}}{\mathrm{~L}_{0}}+\mathrm{b}_{3} \frac{\mathrm{H}_{0}}{\mathrm{wT}}+\mathrm{b}_{4} \frac{\mathrm{H}_{0}}{\mathrm{~d}_{50}}$ & $\frac{\mathrm{X}_{\mathrm{b}}}{\mathrm{d}_{50}}=\mathrm{b}_{0} \mathrm{~m} \mathrm{~b}_{1}\left(\frac{\mathrm{H}_{0}}{\mathrm{~L}_{0}}\right)^{\mathrm{b}_{2}}\left(\frac{\mathrm{H}_{0}}{\mathrm{wT}}\right)^{\mathrm{b}_{3}}\left(\frac{\mathrm{H}_{0}}{\mathrm{~d}_{50}}\right)^{\mathrm{b}_{4}}$ \\
\hline \multicolumn{1}{|c|}{$\mathrm{R}^{2}=0.823$} & Values & Coefficients & Values \\
\hline Coefficients & 2.28 & $\mathrm{~b}_{0}$ & 4.416 \\
\hline $\mathrm{b}_{0}$ & -17.9 & $\mathrm{~b}_{1}$ & 1.21 \\
\hline $\mathrm{b}_{1}$ & 20.6 & $\mathrm{~b}_{2}$ & -0.865 \\
\hline $\mathrm{b}_{2}$ & -2.72 & $\mathrm{~b}_{3}$ & -1.68 \\
\hline $\mathrm{b}_{3}$ & 0.0007 & $\mathrm{~b}_{4}$ & 1.14 \\
\hline $\mathrm{b}_{4}$ & & & \\
\hline
\end{tabular}

Table 7 Regression coefficients obtained from dimensionless regression analysis for $\mathrm{X}_{\mathrm{t}}$.

\begin{tabular}{|c|c|c|c|}
\hline \multicolumn{2}{|c|}{ Multi linear function } & \multicolumn{2}{c|}{ Multi hyperbolic function } \\
\hline$\frac{\mathrm{X}_{\mathrm{t}}}{\mathrm{d}_{50}}=\mathrm{b}_{0}+\mathrm{b}_{1} \mathrm{~m}+\mathrm{b}_{2} \frac{\mathrm{H}_{0}}{\mathrm{~L}_{0}}+\mathrm{b}_{3} \frac{\mathrm{H}_{0}}{\mathrm{wT}}+\mathrm{b}_{4} \frac{\mathrm{H}_{0}}{\mathrm{~d}_{50}}$ & $\frac{\mathrm{X}_{\mathrm{t}}}{\mathrm{d}_{50}}=\mathrm{b}_{0} \mathrm{~m} \mathrm{~b}_{1}\left(\frac{\mathrm{H}_{0}}{\mathrm{~L}_{0}}\right)^{\mathrm{b}_{2}}\left(\frac{\mathrm{H}_{0}}{\mathrm{wT}}\right)^{\mathrm{b}_{3}}\left(\frac{\mathrm{H}_{0}}{\mathrm{~d}_{50}}\right)^{\mathrm{b}_{4}}$ \\
\hline \multicolumn{1}{|c|}{$\mathrm{R}^{2}=0.887$} & Values & Coefficients & Values \\
\hline Coefficients & 5471 & $\mathrm{~b}_{0}$ & 7.34 \\
\hline $\mathrm{b}_{0}$ & -32062 & $\mathrm{~b}_{1}$ & -0.823 \\
\hline $\mathrm{b}_{1}$ & 19712 & $\mathrm{~b}_{2}$ & 1.4 \\
\hline $\mathrm{b}_{2}$ & -6344 & $\mathrm{~b}_{3}$ & -2.27 \\
\hline $\mathrm{b}_{3}$ & 0.13 .6 & $\mathrm{~b}_{4}$ & 1.16 \\
\hline $\mathrm{b}_{4}$ & & & \\
\hline
\end{tabular}

Table 8 Regression coefficients obtained from dimensionless regression analysis for $\mathrm{X}_{\mathrm{s}}$.

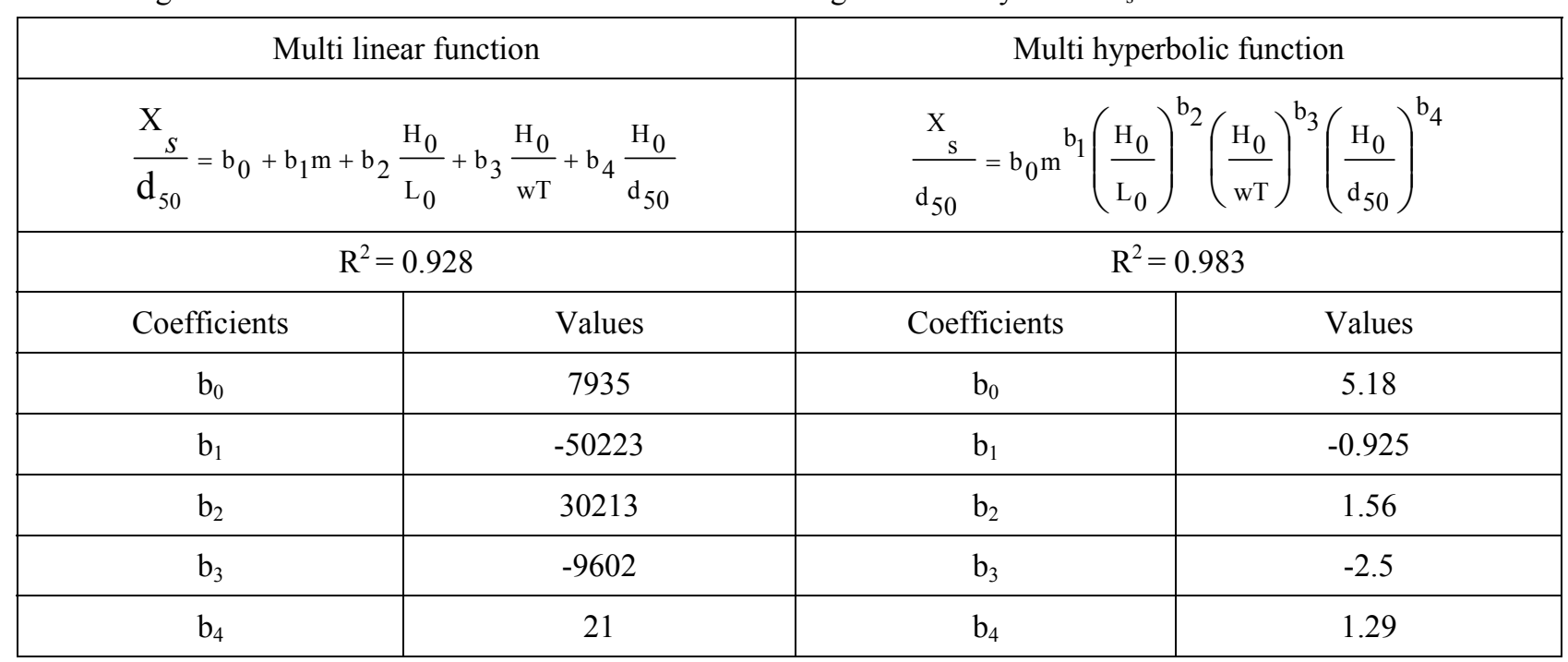


As seen from the Tables 3-5 that, the maximum value of determination coefficient for linear function occurs in the case of $X_{b} / L_{0}$ as dependent variable and $\mathrm{m}, H_{0} / L_{0}, H_{0} / d_{50}, H_{0} / w T$ as independent variables. In the multi-hyperbolic function, the maximum value of determination coefficient is reached in the case of $X_{b} / d_{50}$ as dependent variables and $m, H_{0} / L_{0}$, and $H_{0} / d_{50} H_{0} / w T$ as dependent variables in the linear functions. As seen from the Tables 3-5, the maximum value of determination coefficient for linear and multi hyperbolic function occurs in the case of $\mathrm{X}_{\mathrm{t}} / \mathrm{d}_{50}$ and $\mathrm{X}_{\mathrm{s}} / \mathrm{d}_{50}$ dependent variables and $\mathrm{m}, H_{0} / L_{0}, H_{0} / d_{50}, H_{0} / w T$ as independent variables. In the cause of the maximum value of the determination coefficient, the regression coefficients are presented in Tables 6-8 for multi linear and hyperbolic functions.

According to the determination coefficient in Tables 6-8, multi hyperbolic functions give better results according to the multi linear functions. The equations derived from the dimensionless hyperbolic functions are presented below for bar parameters.

Proposed Equation for $\mathrm{X}_{\mathrm{b}}$

$$
\frac{\mathrm{X}_{\mathrm{b}}}{\mathrm{d}_{50}}=4.416\left(\frac{\mathrm{H}_{0}}{\mathrm{~L}_{0}}\right)^{1.21} \mathrm{~m}^{-0.865}\left(\frac{\mathrm{H}_{0}}{\mathrm{wT}}\right)^{-1.68}\left(\frac{\mathrm{H}_{0}}{\mathrm{~d}_{50}}\right)^{1.14}
$$

Proposed Equation for $\mathrm{X}_{\mathrm{t}}$

$$
\frac{\mathrm{X}_{\mathrm{t}}}{\mathrm{d}_{50}}=7.34\left(\frac{\mathrm{H}_{0}}{\mathrm{~L}_{0}}\right)^{1.4} \mathrm{~m}^{-0.823}\left(\frac{\mathrm{H}_{0}}{\mathrm{wT}}\right)^{-2.27}\left(\frac{\mathrm{H}_{0}}{\mathrm{~d}_{50}}\right)^{1.16}
$$

Proposed Equation for $\mathrm{X}_{\mathrm{s}}$

$$
\frac{\mathrm{X}_{\mathrm{S}}}{\mathrm{d}_{50}}=5.18 \mathrm{~m}^{-0.925}\left(\frac{\mathrm{H}_{0}}{\mathrm{~L}_{0}}\right)^{1.56}\left(\frac{\mathrm{H}_{0}}{\mathrm{wT}}\right)^{-2.50}\left(\frac{\mathrm{H}_{0}}{\mathrm{~d}_{50}}\right)^{1.29}
$$

\section{Horizontal distance between the initial bar point and original shoreline $\left(\mathbf{X}_{\mathrm{b}}\right)$}

Comparisons of proposed equation (Eq. (13) for $\mathrm{X}_{\mathrm{b}}$ and previously developed equations with each other according to the experimental results are shown in Fig. 2. Eq. (13) produces best results which are very close to experimental results as indicated

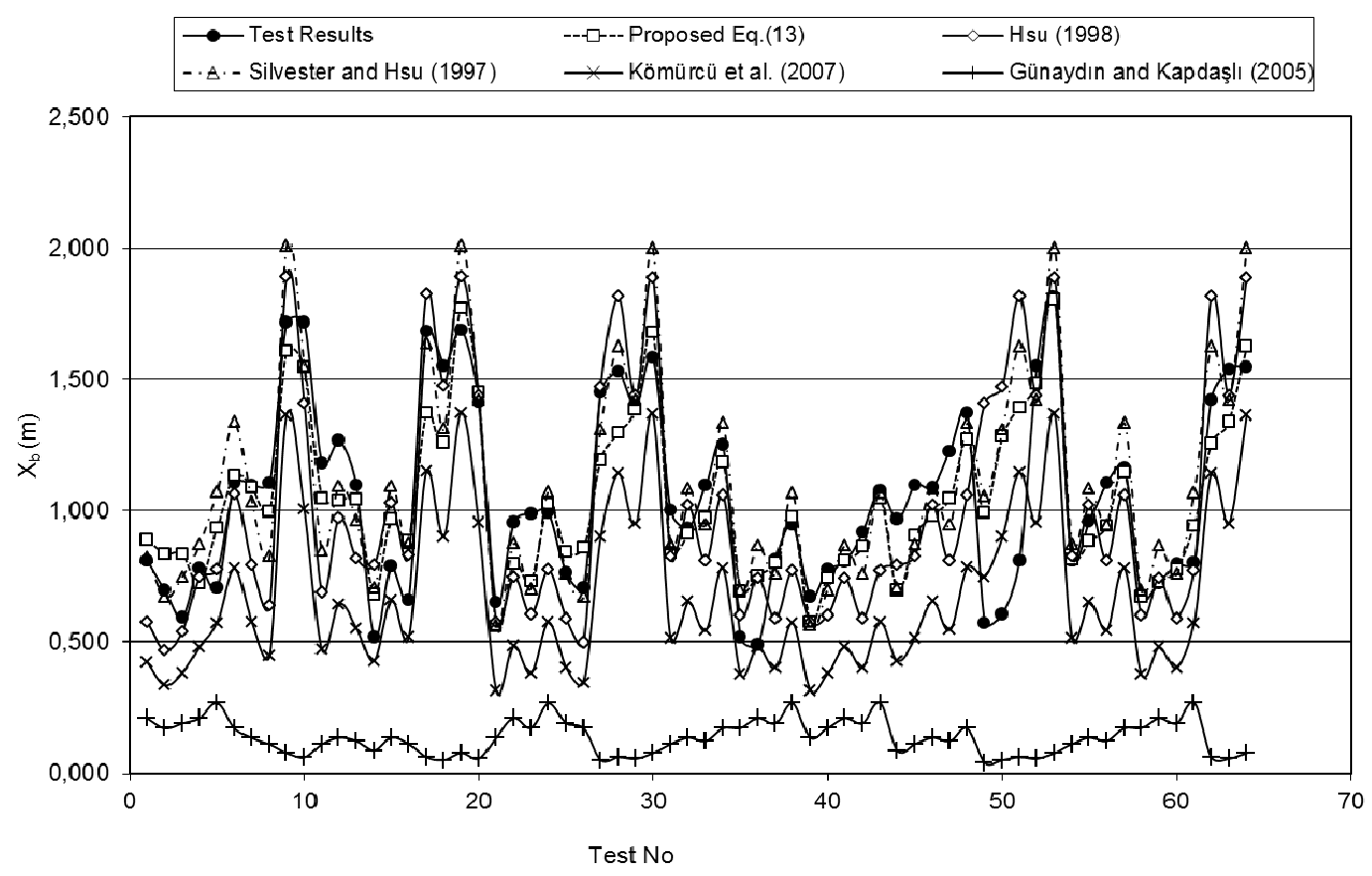

Fig. 2 Comparison of proposed equation with currently used formulae for $\mathrm{X}_{\mathrm{b}}$. 
in Fig. 2. Silvester and Hsu's equations exhibit similar trends with experimental results despite small deviations with respect to other equations. Results of Hsu's equation (Eq. (3)) show a good agreement with experimental results in a certain range. Results of Kömürcü’s equation (Eq. (7)) are different from Hsu's equation (Eq. (3)). Gunaydın and Kapdaslı's equation (Eq. (9)) gives rather different results according to the experimental results and other equations.

\section{Horizontal distance between the bar crest and original shoreline $\left(X_{t}\right)$}

When the proposed equation (Eq. (14)) is compared for horizontal distance between the bar crest and original shoreline $\left(\mathrm{X}_{\mathrm{t}}\right)$, Eq. (14) gives best results according to the experimental results. (Fig. 3). Hsu equations (Eq. (4)) produces best result with respect to other equations (Eqs. (2), (6) and (8)) for experimental conditions when compared with each other. Silvester and Hsu's equation (Eq. (2)) gives also good results according to the experimental results. But Gunaydın and Kapdaslı's equation Eq. (6) and Kömürcü et al.'s equation Eq. (9) shows similar results. Their equations produce different results than the other equations.

\section{Horizontal distance between the final bar point and the original shoreline $\left(X_{s}\right)$}

For horizontal distance between the final bar point and the original shoreline $\left(\mathrm{X}_{\mathrm{s}}\right)$, comparison of best equation (Eq. (15)) and previously developed equations with each other in terms of experimental results are shown in Fig. 4. Considering the equations and the experimental results, a good fit is observed between proposed equation (Eq. (15)) and experimental results. Kömürcü et al. equation (Eq. (9)) results are close to the experimental results and proposed equation (Eq. (15)).

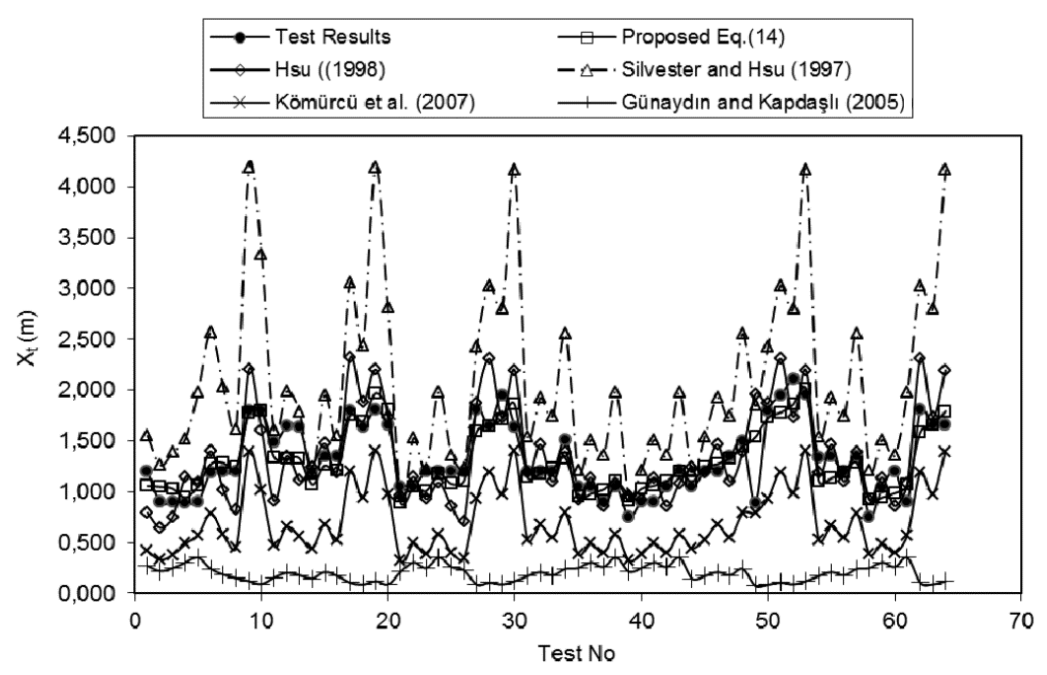

Fig. 3 Comparison of proposed equation with currently used formulae for $\mathrm{X}_{\mathrm{t}}$.

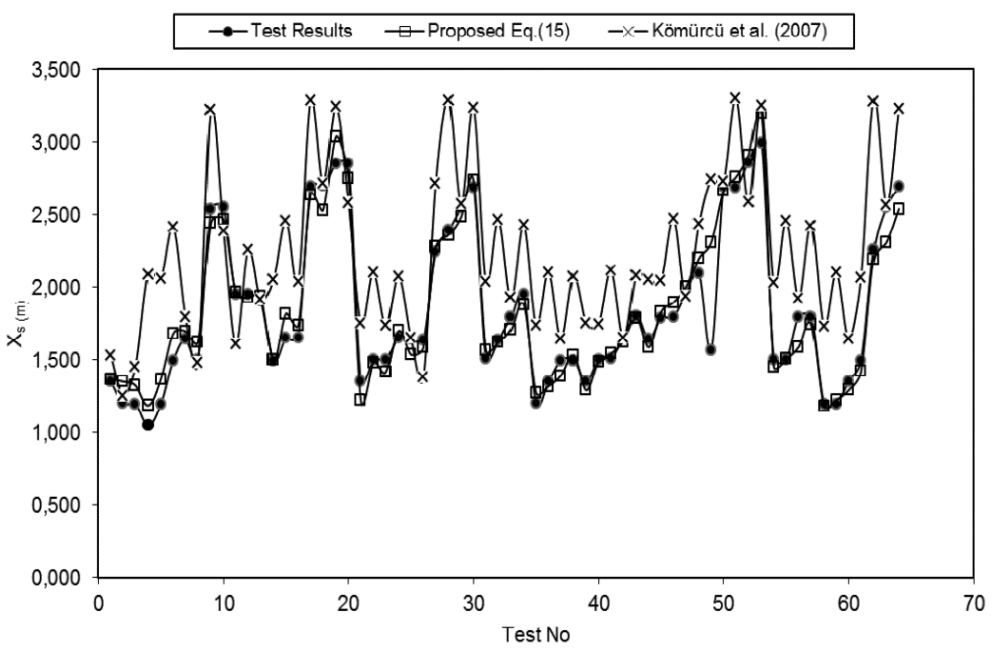

Fig. 4 Comparison of proposed equation with currently used formulae for $\mathrm{X}_{\mathrm{s}}$. 


\section{CONCLUSIONS}

In this study, 64 experiments were carried out to determine bar parameters $\left(\mathrm{X}_{\mathrm{b}}, \mathrm{X}_{\mathrm{t}}, \mathrm{X}_{\mathrm{s}}\right)$ as functions of $\mathrm{H}_{0}, \mathrm{~T}, \mathrm{~m}$ and $\mathrm{d}_{50}$, and the results are given in tables. For each bar parameter, nondimensional equations were obtained by applying nonlinear regression methods. The fittest equations for each bar parameter are obtained by comparing these equations with previously developed equations.

According to the regression analysis results, best equations for $X_{b}, X_{t}, X_{s}$ are Eqs. (13), (14) and (15) respectively. The proposed equations are closer to experimental results than those of previously developed equations. For all parameters, Hsu and Silvester and Hsu's equations give best results according to the experimental results and proposed equations. Gunaydin and Kapdaslı and Kömürcü et al. equations doesn't provide good fit with the other equaitons. It should also be emphasized that a number of experimental data used in this study is greater than those obtained from previous works, hence this helps obtain better results in terms of reliability and reproducibility.

\section{ACKNOWLDEGMENTS}

This work was supported by Çukurova University Research Fund under the Project no. CUMMF2004D5, which is gratefully acknowledged.

\section{REFERENCES}

Dean, R.G., 1973. Heuristics models of sand transport in the surf zone. First Australian Conference on Coastal Engineering. Sydney, Australia 14-17 May 1973. pp.208-214.

Demirci, M., 2006. Experimental investigation of cross-shore profile changes. PhD. CU Natural and Applied Sciences Institute, Adana(in Turkish).

Demirci, M. and Aköz, M.S., 2012. An investigation on the formation of submerged bar under surges in sandy coastal region. China Ocean Engineering, 26(3), pp.535-546.

Gourlay, R.M., 1980. Beaches: profiles, processes and permeability. Proceedings of the $17^{\text {th }}$ Coastal Engineering Conference. Sydney, Australia 23-28 March 1980. pp.1321-1339.

Günaydın, K. and Kapdaşlı, M.S., 2003. Characteristics of coastal erosion geometry under regular and irregular waves. $O c$ ean Engineering, 30(13), pp.1579-1593.

Günaydın, K. and Kabdaşlı, M.S., 2005. Investigation of offshore bar geometry under regular and irregular waves. Journal of Coastal Research, 21(2), pp.374-382.

Hattori, M. and Kawamata, R., 1980. Onshore-offshore transport and beach profile change. Proceedings of the $17^{\text {th }}$ Coastal Engineering Conference. Sydney, Australia 23-28 March 1980. pp.1175-1193.

Hsu, T-W., 1998. Geometric characteristics of storm-beach profiles caused by inclined waves. Ocean Engineering, 25(1), pp.69-84.

Iwagaki, Y. And Noda, H., 1962. Laboratory study of scale effects in two dimensional beach processes. Proceedings of the $8^{\text {th }}$ Coastal Engineering Conference. Mexico City, Mexico 26-29 November 1962. pp.194-210.

Johnson, J.W., 1949. Scale effect in hydraulic model involving wave motion. Transactions, American Geophysical Union, 30(4), pp.517-525.

Kömürcü, M.İ., Özölçer, İ.H., Yüksek, Ö. and Karasu, S., 2007. Determenation of bar parameters caused by cross shore sediment movement. Ocean Engineering, 34(5-6), pp.685-695.

Larson, M., 1996. Model of beach profile change under random waves. Journal of Waterway, Port, Coastal and Ocean Engineering, 122(4), pp.172-181.

Larson, H. and Kraus, N.C., 1989. Numerical model for simulating storminduced beach change(SBEACH), Report 1, empirical foundation and model development. Technical Report, CERC-TR-89-9-RPT-1. US Army.

Nayak, I.V., 1970. Equilibrium profiles of model beaches. Proceedings of the $12^{\text {th }}$ Coastal Engineering Conference. Washington, USA 13-18 September 1970. pp.1321-1340.

Noda, E.K., 1972. Equilibrium beach profile scale model relationships. Journal of the Waterways, Harbors and Coastal Engineering Division, 98(4), pp.511-528. 
Özölçer, İ., 2008. An experimental study on geometric characteristics of beach erosion profiles. Ocean Engineering, 35(1), pp.17-27.

Rozynski, G., 2003. Data-driven modeling of multiple longshore bars and their interactions. Coastal Engineering, 48(3), pp.151-170.

Ruessink, B.G., Bell, P.S., Enckevort, I.M.J. and Aarninkhof, S.G.J., 2002. Nearshore bar crest location quantified from time-averaged X-band radar images. Coastal Engineering, 45(1), pp.19-32.

Saville, T. Jr., 1957. Scale effects in two dimensional beach studies. Proceedings of the $7^{\text {th }}$ International Association for Hydraulics Research Congress. Lisbon, Portugal 7-9 January 1957. pp.A3-1-A3-10.

Sawaragi, T. and Deguchi, I., 1980. On-offshore sediment transport rate in the surf zone. Proceedings of the $17^{\text {th }}$ Coastal Engineering Conference. Sydney, Australia 23-28 March 1980. pp.1194-1214.

Silvester, R. and Hsu, J.R.C., 1997. Coastal stabilization. Advanced series on ocean engineering. Vol. 14. World Scientific Publishing.

Sunamura, T. and Horikawa, K., 1974. Two-dimensional beach transformation due to waves. Proceedings of the $14^{\text {th }}$ Coastal Engineering Conference. Copenhagen, Denmark 24-28 June 1974. pp.920-938.

Watanabe, A., Riho, Y. and Horikawa, K., 1980. Beach profiles and on-offshore sediment transport. Proceedings of the $17^{\text {th }}$ Coastal Engineering Conference. Sydney, Australia 23-28 March 1980. pp.1106-1121. 